\title{
Refraction and eye anterior segment parameters in schizophrenic patients
}

\section{Refração e parâmetros do segmento anterior ocular em pacientes com esquizofrenia}

\author{
Tongabay Cumurcu ${ }^{1}$, Sinem Keser ${ }^{1}$, Birgul Elbozan Cumurcu², Abuzer Gunduz ${ }^{1}$, Sukri Kartalcl ${ }^{2}$
}

\begin{abstract}
Purpose: To evaluate the difference in terms of refractive errors and anterior segment parameters between schizophrenic patients and healthy volunteers.

Methods: This study compared 70 patients (48 men) who were diagnosed with schizophrenia with a control group of 60 ( 35 men) who were similar in terms of age, gender, education, and socioeconomic level. Anterior segment examination was performed using a Scheimflug system. Axial length and lens thickness (LT) were measured using optic biometry. The following tests were administered to the psychiatric patient group: Brief Psychiatric Rating Scale (BPRS), Scale for the Assessment of Negative Symptoms (SANS), and Scale for the Assessment of Positive Symptoms (SAPS).

Results: Mild myopia was detected in both the schizophrenic and control groups, with no statistically significant difference $(p>0.005)$. Corneal volume (CV), anterior chambervolume (ACV), anterior chamber depth (ACD), and central corneal thickness (CCT) values were lower in the schizophrenic group, and there was a statistically significant between-group difference $(p=0.026, p=0.014, p=0.048$, and $p=0.005$, respectively). LT was greater in schizophrenics, and the difference was found to be statistically significant $(p=0.006)$. A statistically significant negative correlation was found between SAPS and cylinder values $(p=0.008)$. The axial eye length, cylinder value, pupil diameter, mean keratometric value, and anterior chamber angle revealed no statistically significant difference between the groups $(p>0.05)$. Conclusion: No statistically significant difference was detected in terms of refraction disorders between schizophrenics and the healthy control group, while some differences in anterior chamber parameters were present. These results demonstrate that schizophrenics may exhibit clinical and structural differences in the eye.
\end{abstract}

Keywords: Schizophrenia; Refractive errors/complications; Anterior eye segment/ pathology; Biometry

\section{RESUMO}

Objetivo: Avaliar seexistem diferenças em relação aos erros refracionais e parâmetros do segmento anterior entre pacientes com esquizofrenia e voluntários saudáveis. Métodos: Este estudo comparou 70 pacientes diagnosticados com esquizofrenia (48 homens) com um grupo controle de 60 pacientes, semelhantes em relação à idade, sexo, escolaridade enível socioeconômico (35 homens). Oexame do segmento anterior foi realizado com o sistema Scheimflug; os comprimentos axiais do ol ho e a espessura do cristalino foram avaliadas por meio de biometria óptica. Os seguintes testes foram aplicados ao grupo de pacientes psiquiátricos: Brief Psychiatric Rating Scale (BPRS), Scale for the Assessment of Negative Symptoms (SANS), e Scale for the Assessment of Positive Symptoms (SAPS).

Resultados: Miopia leve foi detectada em ambos os grupos de esquizofrenia e de controle, sem diferença estatisticamente significativa $(p>0,005)$. Volume de córnea $(C V)$, volume da câmara anterior (ACV), profundidade da câmara anterior (ACD) e paquimetria central da córnea (CCT) apresentaram valores menores no grupo de esquizofrênicos e houve diferença estatisticamente significativa entre os dois grupos ( $p=0,026, p=0,014, p=0,048$ e $p=0,005$, respectivamente). A espessura do cristalino (LT) foi maior em esquizofrênicos e a diferença foi estatisticamente significativa $(p=0,006)$. Foi encontrada uma correlação negativa estatisticamente significativa entre SAPS e os valores cilíndricos $(p=0,008)$. O comprimento axial do olho, o valor do cilindro, o diâmetro pupilar, a ceratometria média e o ângulo da câmara anterior não revelaram nenhuma diferença estatística entre os grupos $(p>0,05)$.

Conclusões: Não foi detectada diferença estatisticamente significativa em relação aos transtornos de refração entre os esquizofrênicos e o grupo controle, enquanto algumas diferenças nos parâmetros de câmara anterior estavam presentes. Estes resultados demonstram que esquizofrénicos podem apresentar diferenças clínicas e estruturais do olho.

Descriotres: Esquizofrenia; Erros de refração/complicações; Segmento anterior do olho/patologia; Biometria

\section{INTRODUCTION}

Schizophrenia is characterized by distorted thought, hallucinations, and reduced ability to feel normal emotions. It has a lifetime prevalence of approximately $1 \%$ and has long been associated with the environment and hereditary factors ${ }^{(1,2)}$. Dopamine may be involved in the pathophysiology as all effective pharmacological treatments for the disorder affect dopamine neurotransmission ${ }^{(2)}$.

Myopia is a visual disorder where nearby objects are seen clearly but distant objects appear blurred, and it is the most common refractive error ${ }^{(3)}$.

Studies have demonstrated that genetic factors make an important contribution to the etiology of both myopia and schizophrenia ${ }^{(4,5)}$.
In addition, the suggested role of dopamine in the emmetropization process and pathophysiology of schizophrenia is known ${ }^{(2,6)}$. According to the dopamine hypothesis, the lack of dopamine in the brain may interfere with the emmetropization process ${ }^{(6)}$.

Recently, Caspi et al. ${ }^{(7)}$ reported that the presence of refractive errors in adolescence is related to a lower risk of schizophrenia in light of the dopamine hypothesis and genetic factors. However, anterior segment parameters related with refraction were not evaluated in schizophrenic patients in their study.

This study aimed to evaluate differences between schizophrenic patients and healthy volunteers with regard to refractive errors and anterior segment parameters. To the best of our knowledge, there is
Submitted for publication: September 11, 2014

Accepted for publication: March 11, 2015

Department of Ophthalmology, Inonu University School of Medicine, Malatya, Turkey.

2 Department of Psychiatry, Inonu University School of Medicine, Malatya, Turkey.
Funding: No specific financial support was available for this study.

Disclosure of potential conflicts of interest: None of the authors have any potential conflict of interest to disclose.

Corresponding author: Tongabay Cumurcu. Inonu University - School of Medicine - Malatya - Turkey E-mail: tongabay@superonline.com

Approved by the following research ethics committee: Institutional Review Board of the Inonu University School of Medicine (31-07-2012/158). 
no study on anterior segment parameters in schizophrenic patients, and only one study has reported refractive errors in schizophrenic patients ${ }^{(7)}$.

\section{METHODS}

The study group included 70 schizophrenic patients evaluated at the Eye Outpatient Clinic of Inonu University, Department of Ophthalmology in Turkey. All 130 subjects provided informed consent to participate in the study after they were informed about the aim and details of the cross-sectional study. The control group included 60 age-, sex-, and educational level-matched subjects who were other patients visiting the same institution. This study was approved by the local ethics committee. The Institutional Review Board of the Inonu University School of Medicine approved the study protocol, which specified study conduct in compliance with the tenets of the Declaration of Helsinki.

\section{INCLUSION CRITERIA}

The inclusion criteria for schizophrenic patients included age of 18-65 years, diagnosis of schizophrenia on the basis of the Diagnostic and Statistical Manual for Mental Disorders, Fourth Edition Revised Form (DSM-IV-TR) criteria, treatment with antipsychotic drug (typical, atypical or combined) for at least 2 years, no exposure to electroconvulsive therapy (ECT), and the absence of a comorbid medical condition or disease.

\section{EXCLUSION CRITERIA}

Exclusion criteria for both schizophrenic and control groups included anamnesis of eye surgery or eye trauma, refractive surgery, corneal pathology, uveitis, glaucoma, posterior segment pathology, or a topical drug usage that affects anterior segment parameters. Patients who were physically impaired and had difficulties in conversing or completing the scale, patients who received treatment for any other psychiatric disorders according to the DSM-IV-TR, patients with dementia, and patients who had undergone intraocular surgery, had corneal pathologies, or had a history of ocular trauma were excluded from the study. Subjects who had a history of refractive surgery or amblyopia were also excluded from the study.

\section{Patient assessment}

Each subject underwent a complete ophthalmic evaluation, including detailed ophthalmic history, visual acuity testing using Snellen's chart, slit-lamp examination, Goldmann's applanation tonometry, gonioscopy using Goldmann's three-mirror lens, visual field examination, and dilated fundus examination.

The patient group consisted of schizophrenic patients aged 18-65 years who had been taking antipsychotic medication for at least 2 years and whose schizophrenia diagnosis was based on the DSM-IV-TR diagnostic criteria ${ }^{(8)}$.

All subjects in the study and control groups were interviewed by a psychiatrist. The dynamic refraction assay of patient and control groups was applied, and it was accepted $\pm 0.25 \mathrm{D}$ and below as emmetropia.

All patients were evaluated using Pentacam (Oculus ${ }^{\circledR}$, Pentacam, Germany). All measurements were obtained under standard dim light conditions and without dilation. The Pentacam CES system is based on a $180^{\circ}$ rotating Scheimpflug camera that can take 12-50 single images to reconstruct the anterior chamber. Anterior segment reconstructions were produced with 25 single captures in this study. After completing a scan, the Pentacam software constructs a three-dimensional image of the anterior segment and calculates the anterior chamber parameters $^{(9)}$. This imaging provides measurements of anterior chamber depth $(A C D)$, anterior chamber volume (ACV), anterior chamber angle (ACA) width, and pupil size.

The software-provided values, automatically calculated using 25 images from each patient eye, were used for ACA width, ACV, and
ACD evaluation. The Pentacam system measures ACD from the endothelium to the anterior lens surface without including the corneal thickness, whereas ACV is measured from the posterior cornea to the anterior lens surface ${ }^{(10)}$

The axial length (Alx) measurements and lens thickness (LT) were determined by optic biometry (Lenstar LS 900; Haag Streit Köniz, Switzerland). Alx measurement was accepted as the distance from the anterior cornea to the retina. The Lenstar LS 900 biometer uses optical low-coherence reflectometry (OLCR) with an $820 \mu \mathrm{m}$ superluminescent diode. Alx measurements were performed with the noncontact method using Lenstar LS 900 (11).

Sociodemographic and Disorder Inquiry Form: This inquiry was prepared by the investigators and included questions on gender, age, education, any physical disorder requiring continuous treatment, psychiatric history, and family history of associated disorders. The form was read out to participants and their family members, and the information was recorded by the investigators.

Brief Psychiatric Rating Scale (BPRS): BPRS is a rating scale for measuring psychiatric symptoms such as depression, anxiety, hallucinations, and unusual behavior. Each symptom is rated between 1 and 7, and 18 or 24 symptoms are scored depending on the version. BPRS was developed by Overall and Gorham in 1962, and a validated Turkish translation is available ${ }^{(12)}$.

Scale for the Assessment of Negative Symptoms (SANS): SANS, developed by Andreasen ${ }^{(13)}$, assesses negative symptoms, including affective blunting, alogia (impoverished thinking), avolition/apathy, anhedonia/asociality, and disturbance of attention, in schizophrenic patients. The final symptom complexes seem to have less obvious relevance to negative symptoms than the other four complexes. Assessments are conducted on a six-point scale $(0=$ not at all to $5=$ severe). The Turkish version was validated and reported to be reliable by Erkoç et al..(14).

Scale for the Assessment of Positive Symptoms (SAPS): This scale is designed to assess positive symptoms, principally those that occur in schizophrenia, and it is intended to serve as a complementary instrument to the SANS. Positive symptoms include hallucinations, delusions, bizarre behavior, and positive formal thought disorder. SAPS was developed by Andreasen in 1984(15). The Turkish version was validated and reported to be reliable by Erkoç et al..(16).

\section{SAMPLe SIZE}

Based on post hoc power analysis for LT and outcome variables, group sample sizes of 60 and 70 were considered necessary to achieve $84 \%$ power to detect a difference of -0.2 between the null hypothesis that both group means are 3.8 and the alternative hypothesis that the mean of Group 2 is 4.0, with estimated group standard deviations of 0.3 and 0.4 and a significance level (alpha) of 0.05 using a two-sided two-sample t-test.

SPSS version 17.0 was used for statistical analysis of data. The chi-square test was used for between-group evaluation of the categorical variables of gender, education level, and economic level between the two groups. The mean, standard deviation, and percentage values were calculated. An independent samples t-test was used to determine the difference between the two groups. Pearson Correlation test was used to determine the amount and direction between variables, with $p<0.05$ considered statistically significant.

\section{RESULTS}

The mean age was $35.34 \pm 10.13$ years in the schizophrenic group and $32.63 \pm 7.90$ years in the control group. The 70 subjects in the schizophrenic group had a women: men distribution of $22(31.4 \%)$ to $48(68.6 \%)$, whereas there were 25 (41.7\%) women and $35(58.3 \%)$ men in the control group. There was no significant between-group difference with regard to age, sex, and duration of education ( $p>0.05$ ). Sociodemographic data of the groups are presented in table 1. 
A comparison of the data for the study groups for refractive errors, Alx measurements, and anterior segment parameters is presented in table 2 .

The mean BPRS, SAPS, and SANS values were $28.77 \pm 10.91,41.52$ $\pm 15.59,50.45 \pm 23.89$, respectively, in schizophrenic men, whereas they were $33.86 \pm 27.41,49.95 \pm 24.28$, and $56.90 \pm 27.74$, respectively, in schizophrenic women.

The correlation between age, refraction, Alx, and anterior segment parameters and the BPRS, SAPS, and SANS values in the schizophrenic group is presented in table 3. Only the correlation between cylindrical equivalent and the SAPS values was statistically significant. This means there is an increased tendency for astigmatism when the negative symptoms of the disease increase.

There were 18 subjects (25.7\%) with emmetropia and 52 subjects $(74.3 \%)$ with ametropia in the schizophrenic group and 24 subjects (40\%) with emmetropia and 36 subjects (60\%) with ametropia in the control group. When the patient and control groups were compared with regard to the incidence of refractive errors, there was no statistically significant difference between the groups ( $p=0.082$ ).

The mean duration of disease was $10.40 \pm 6.66$ (range 2-22) years in the patient group. Correlations between the duration of disease and refractive error, Alx, and anterior segment parameters are presented in table 4.

\section{Table 1. Sociodemographic data of study groups}

\begin{tabular}{lccc}
\hline & Patient $(\boldsymbol{n}=\mathbf{7 0})$ & Control $(\boldsymbol{n}=\mathbf{6 0})$ & $\boldsymbol{p}$ value \\
\hline Age (years) & $35.34 \pm 10.13$ & $32.63 \pm 7.90$ & \\
Mean \pm SD $(95 \% \mathrm{Cl})$ & $(32.92-37.75)$ & $(30.59-34.67)$ & 0.09 \\
Sex, $n(\%)$ & & & \\
Female & $22(31.4 \%)$ & $25(41.7 \%)$ & \\
Male & $48(68.6 \%)$ & $35(58.3 \%)$ & 0.22 \\
Socioeconomic status, $n(\%)$ & & & \\
Low & $23(32.9 \%)$ & $23(38.3 \%)$ & \\
Moderate & $37(52.9 \%)$ & $28(46.7 \%)$ & \\
High & $10(14.3 \%)$ & $9(15.0 \%)$ & \\
Levels of education, $n(\%)$ & & & \\
Primary school & $20(28.6 \%)$ & $21(35.0 \%)$ & \\
High school & $39(55.7 \%)$ & $30(50.0 \%)$ & \\
University & $11(15.7 \%)$ & $9(15.0 \%)$ & 0.72 \\
\hline
\end{tabular}

Note $=$ mean \pm SD (95\% Cl for mean).

$\mathrm{t}=$ independent samples test; $\mathrm{n}=$ number of subjects; $\mathrm{SD}=$ standard deviation.
Eight patients were on treatment with only typical antipsychotics (11.4\%), 37 patients with only atypical antipsychotics (52.8\%), and 25 patients with both typical and atypical antipsychotics (35.7\%). The dosage of typical and atypical antipsychotic drugs at a chlorpromazine-equivalent (mg/day) was $307.41 \pm 180.60$ and $386.47 \pm 281.51$, respectively.

In addition to antipsychotics, 18 patients (25.7\%) were on treatment with biperiden. Benzodiazepines (alprazolam and diazepam) were used by four patients (5.7\%). Two patients (2.8\%) were on treatment with a selective serotonin reuptake inhibitor (escitalopram).

The percentage of patients of this study using each antypsychotic drug was determined. Typical antipsychotic drug use was as follows: four patients (5.7\%) on zuclopentixol, 26 patients (37.1\%) on haloperidol, and three patients (4.3\%) on flupentixol. Atypical antipsychotic usage included: 28 patients (40\%) on risperidone, 13 patients (13\%) on olanzapine, 10 patients (14.3\%) on aripiprazole, eight patients (11.4\%) on amilsulpiride, 14 patients (20\%) on clozapine, five patients (7.1\%) on quetiapine, and one patient (1.4\%) on ziprasidone.

\section{DISCUSSION}

There are many hypotheses for the etiology of schizophrenia such as genetic factors and imbalance of biochemical mediators, of which the most important one is dopamine ${ }^{(17,18)}$. Genetic factors and dopamine have been determined to play a role in the etiologies of both refractive errors and schizophrenia ${ }^{(7)}$. Dopamine plays an important role in the emmetropization process and inhibits the development of myopia ${ }^{(7)}$. In addition, Caspi et al..$^{(7)}$ have reported a lower frequency of myopia in schizophrenic patients than in healthy subjects. In that stu$d y$, the rate of refractive errors in schizophrenic patients, their nonschizophrenic siblings, and control siblings was $1.00 \%, 3.58 \%$, and $5.07 \%$ respectively. Caspi et al. ${ }^{(19)}$ have reported a lower incidence of refractive errors in schizophrenic patients and their nonschizophrenic twins, suggesting an important role of genetics in the development of refractive errors. Saw et al. reported that the low prevalence of myopia could be related to the reduced tendency for near work in schizophrenic patients. In our study, we did not find any difference between the groups in terms of refractive error.

Many studies have reported differences with regard to various parts of the body in schizophrenic patients ${ }^{(20-22)}$. The frequencies of specific dermatoglyphic patterns were found to be statistically significantly different between schizophrenics and healthy controls with respect to hand and gender ${ }^{(20)}$. The incidence of agenesis of the corpus callosum, large cavum septum pellicidum, or absence of adhesio interthalamica gray matter heterotopia is higher in schizophrenic patients ${ }^{(21,22)}$. Similarly, we found many differences in the anterior seg-

Table 2. Between-group comparison of refractive errors, axial length measurements (Alx), and anterior segment parameters

\begin{tabular}{|c|c|c|c|}
\hline & Patient $(n=70)$ & Control $(n=60)$ & \\
\hline & Mean \pm SD $(95 \% \mathrm{Cl})$ & Mean \pm SD $(95 \% \mathrm{Cl})$ & $p$ value \\
\hline Spherical equivalent & $-0.84 \pm 2.13(-1.35-0.33)$ & $-0.73 \pm 1.90(-1.22-0.24)$ & 0.760 \\
\hline Axial length (mm) & $23.57 \pm 1.04(23.32-23.82)$ & $23.58 \pm 1.22(23.26-23.89)$ & 0.960 \\
\hline Lens thickness (mm) & $3.99 \pm 0.36(3.90-4.07)$ & $3.82 \pm 0.29(3.74-3.90)$ & $0.006^{*}$ \\
\hline Corneal volume $\left(\mathrm{mm}^{3}\right)$ & $59.78 \pm 4.27(58.76-60.79)$ & $61.31 \pm 3.30(60.45-62.16)$ & $0.026^{*}$ \\
\hline Anterior chamber depth (mm) & $2.94 \pm 0.34(2.86-3.02)$ & $3.07 \pm 0.38(2.97-3.17)$ & $0.048^{*}$ \\
\hline Anterior chamber angle & $35.15 \pm 5.72(33.79-36.52)$ & $35.60 \pm 5.03(34.30-36.90)$ & 0.630 \\
\hline Pupil diameter (mm) & $2.79 \pm 0.48(2.67-2.90)$ & $2.93 \pm 0.48(2.80-3.05)$ & 0.100 \\
\hline Central corneal thickness & $538.55 \pm 31.26(531.10-546.01)$ & $555.56 \pm 36.17(546.22-564.91)$ & $0.005^{*}$ \\
\hline Mean keratometric value & $43.30 \pm 1.65(42.91-43.70)$ & $43.44 \pm 1.76(42.99-43.90)$ & 0.630 \\
\hline
\end{tabular}

$\mathrm{t}=$ independent samples test; $n=$ number of subjects; SD= standard deviation; mean \pm SD (95\% Cl for Mean). 
Table 3. Correlation between age, refraction, axial length (Alx), and anterior segment parameters and the Brief Psychiatric Rating Scale (BPRS), Scale for the Assessment of Positive Symptoms (SAPS), and Scale for the Assessment of Negative Symptoms (SANS) values in the schizophrenic group

\begin{tabular}{|c|c|c|c|c|c|c|}
\hline & \multicolumn{2}{|c|}{$\begin{array}{c}\begin{array}{c}\text { BPRS } \\
(n=70)\end{array} \\
\end{array}$} & \multicolumn{2}{|c|}{$\begin{array}{c}\begin{array}{c}\text { SAPS } \\
(n=70)\end{array} \\
\end{array}$} & \multicolumn{2}{|c|}{$\begin{array}{c}\text { SANS } \\
(\mathrm{n}=70)\end{array}$} \\
\hline & $\mathbf{r}$ & $\mathbf{p}$ & $\mathbf{r}$ & $\mathbf{p}$ & $\mathbf{r}$ & $\mathbf{p}$ \\
\hline Age & -0.09 & 0.45 & 0.004 & 0.970 & -0.190 & 0.10 \\
\hline Spherical equivalent & -0.03 & 0.80 & 0.100 & 0.370 & -0.210 & 0.07 \\
\hline Cylindrical equivalent & -0.15 & 0.19 & -0.310 & $0.008^{*}$ & -0.020 & 0.84 \\
\hline Alx & -0.01 & 0.89 & -0.120 & 0.300 & 0.004 & 0.97 \\
\hline Lens thickness & -0.15 & 0.19 & -0.080 & 0.470 & -0.060 & 0.58 \\
\hline Corneal volume & 0.13 & 0.28 & -0.050 & 0.460 & -0.110 & 0.33 \\
\hline Anterior chamber volume & 0.03 & 0.77 & -0.100 & 0.370 & -0.050 & 0.67 \\
\hline Anterior chamber depth & 0.01 & 0.92 & -0.110 & 0.330 & -0.120 & 0.29 \\
\hline Anterior chamber angle & -0.03 & 0.78 & -0.050 & 0.670 & 0.020 & 0.85 \\
\hline Pupil diameter & 0.14 & 0.24 & 0.010 & 0.870 & -0.090 & 0.42 \\
\hline Central corneal thickness & 0.20 & 0.09 & 0.080 & 0.460 & -0.140 & 0.24 \\
\hline Mean keratometry & -0.13 & 0.28 & -0.190 & 0.110 & -0.170 & 0.15 \\
\hline
\end{tabular}

$r=$ Pearson's correlation Test; $n=$ number of subjects.

Table 4. Correlation between duration of disease and refractive error with Alx and anterior segment parameters

\begin{tabular}{lcc}
\hline & \multicolumn{2}{c}{ Duration of disease } \\
\cline { 2 - 3 } & $\boldsymbol{r}$ & $\boldsymbol{p}$ \\
\hline Spherical equivalent & 0.32 & $0.0060^{*}$ \\
Cylindrical equivalent & 0.023 & 0.8500 \\
Axial length & -0.19 & 0.1000 \\
Lens thickness & 0.73 & $0.0001^{*}$ \\
Corneal volume & -0.14 & 0.2300 \\
Anterior chamber volume & -0.55 & $0.0001^{*}$ \\
Anterior chamber depth & -0.48 & $0.0001^{*}$ \\
Anterior chamber angle & -0.23 & $0.0050^{*}$ \\
Pupil diameter & -0.29 & $0.0130^{*}$ \\
Central corneal thickness & 0.032 & 0.7900 \\
Mean keratometry & 0.29 & $0.0130^{*}$ \\
\hline
\end{tabular}

${ }^{*}=$ statistically significant, $p<0.05$.

ment parameters of the eye such as central corneal thickness (CCT), $A C V, A C D, L T$, and $C V$.

Some ocular problems in schizophrenic patients such as dysfunction of saccadic eye movements and stereopsis disorders (particularly in schizophrenic patients with visual hallucinations) have been reported in the literature ${ }^{(23,24)}$. Recently, Meier et al. demonstrated a microvascular abnormality in schizophrenia by retinal imaging ${ }^{(25)}$. According to this study, retinal venules were wider in schizophrenic patients than in controls, suggesting a microvascular abnormality reflective of insufficient brain oxygen supply. In addition, Shiloh et al. have reported a decrease in the corneal temperature in patients with treatment-resistant paranoid schizophrenia and concluded that this situation may be attributable to the thermoregulation effect of dopamine ${ }^{(26)}$. Compared with controls, we also found a statistically significant decrease in CV and CCT in schizophrenic patients, which may be attributable to genetic factors and/or the emmetropization effect of dopamine. In addition, the decreased ACA, ACD, and increased LT in schizophrenic patients may be associated with these factors. We have demonstrated changes in $A C D, L T, C V$, and $C C T$ and no difference in Alx, ACA, PD, and Km in schizophrenic patients.

Shiloh et al. have reported a lower corneal temperature in schizophrenics who use antipsychotic drugs than in those who do not use them ${ }^{(27)}$. Because all the schizophrenic patients in our study had used antipsychotic drugs, we could not compare anterior segment parameters between patients who did and did not use antipsychotics. One limitation of our study is that our patient group had received antipsychotic drugs and this may have affected some of the parameters assessed. However, we believe it would be ethically incorrect to discontinue drug use in this patient population for the purpose of scientific study. Only two patients had started using antipsychotic drugs before the age of 20 years; however, there were no problems detected on ophthalmologic examination in these two patients. Emetropization is expected to be completed by this age, although we believe that the refractive status will not be affected.

BPRS, SAPS, and SANS have been used in psychiatry clinics for the evaluation of schizophrenics. We found only one statistically significant correlation between the cylindrical equivalent and the SAPS values. An increase in negative symptoms may increase the tendency for astigmatism. On the other hand, there was no statistically significant correlation between the spherical equivalent and BPRS, SAPS, or SANS.

The correct diagnosis and management of patients with glaucoma is dependent on an accurate determination of intraocular pressure (IOP). Kruse Hansen et al. have reported a positive linear correlation between CCT and IOP(28). IOP measured by applanation may be overestimated or underestimated in thick or thin corneas, respectively. CCT measurements were lower in schizophrenic patients than the control group in the present study; however, we could not find any difference between the two groups with regard to IOP measurements. We also found no difference between the two groups with regard to ACA measurements.

In addition, the reduced level of CV and CCT is clinically important in schizophrenic patients who require refractive surgery. Moreover, the reduced level of CV and CCT indicates that refractive surgery involves a higher risk in schizophrenic patients ${ }^{(29)}$.

Furthermore, in the present study, the LT level was found to be increased, whereas the ACV and ACD levels were reduced in schizophrenic patients. These findings are very important for glaucoma, cataract, and anterior segment surgeries. In addition, this condition reflects an increased risk potential for glaucoma, cataract, and anterior segment surgeries in schizophrenic patients ${ }^{(29)}$. We found no statistically significant between-group difference with regard to the frequency of refractive error or measured values in our study. Caspi et al. have reported a lower frequency of myopia in schizophrenic patients than in healthy subjects ${ }^{(7)}$. Moreover, we found a slight myopic shift but no statistically significant difference between the groups in the present study.

Finally, this study pioneers the investigation of anterior segment parameters (CV, CCT, LT, ACV, ACD, ACA, and Alx) in schizophrenic patients.

\section{REFERENCES}

1. Petronis A. The origin of schizophrenia: genetic thesis, epigenetic antithesis, and resolving synthesis. Biol Psychiatry. 2004;55(10):142-6.

2. Sadock BJ, Sadock VA. Kaplan and Sadock's synopsis of psychiatry. Philadelphia: Lippincott Williams and Wilkins; 2003.

3. Morgan IG. The biological basis of myopic refractive error. Clin Exp Optom. 2003; 86(5):276-88

4. Hammond CJ, Snieder H, Gilbert CE, Spector TD. Genes and environment in refractive error: the twin eye study. Invest Ophthalmol Vis Sci. 2001;42(6):1232-6

5. Gottesman II, Gould TD. The endophenotype concept in psychiatry: etymology and strategic intentions. Am J Psychiatry. 2003;160(4):636-45.

6. Stone RA, Lin T, Laties AM, luvone PM. Retinal dopamine and form-deprivation myopia. Proc Natl Acad Sci USA. 1989:86(2):704-6.

7. Caspi A, Vishne T, Reichenberg A, Weiser M, Dishon A, Lubin G,et al. Refractive errors and schizophrenia. Schizophr Res. 2009:107(2-3):238-41. 
8. American Psychiatric Association. Diagnostic and Statistical Manuel of Mental Disorders. 4th ed. Text Revision. Washington DC: American Psychiatric Association; 2000.

9. Cumurcu T, Sener S, Ozsoy E, Doganay S. Changes in anterior chamber parameters with the Pentacam rotating Scheimpflug and axial length measurements by ultrasound in patients who use isotretinoin. Curr Eye Res. 2012;37(5):395-8.

10. Uçakhan OO, Ozkan M, Kanpolat A. Anterior chamber parameters measured by the Pentacam CES after uneventful phacoemulsification in normotensive eyes. Acta Ophthalmol. 2009;87(5):544-8.

11. Hoffer KJ, Shammas HJ, Savini G. Comparison of 2 laser instruments for measuring axial length. J Cataract Refract Surg. 2010;36(4):644-8.

12. Overall JE, Gorham DR. The brief psychiatric rating scale. Psychol Rep. 1962;10:81-799.

13. Andreasen NC. Scale for the assessment of negative symptoms (SANS). lowa City, IA: College of Medicine, University of lowa; 1984a.

14. Erkoc S, Arkonaç O, Ataklı C, Ozman E. [The reliability and validity of scale for the assessment of the negative symptoms]. Düşünen Adam. 1991;4:16-9. Turkish.

15. Andreasen NC. Scale for the assessment of positive symptoms (SANS). lowa City. IA: College of Medicine, University of lowa; 1984b.

16. Erkoc S, Arkonaç O, Ataklı C, Ozman E. [Reliability and validity of scale for the assessment of the positive symptoms]. Düşünen Adam. 1991:4:20-4. Turkish.

17. Ebert MH, Loosen PT, Nurcombe B, Leckman JF, eds. Current diagnosis \& treatment psychiatry. $2^{\text {nd }}$ ed. New York, NY: McGraw Hill; 2008. Cap. 36.

18. Lieberman AJ. Textbook of schizophrenia. Washington (DC): The American Psychiatric Publishing; 2006

19. Saw SM. A synopsis of the prevalence rates and environmental risk factors for myopia. Clin Exp Optom. 2003;86(5):289-94.
20. Özyurt B, Songur A, Sarsılmaz M, Akyol Ö, Namlı M, Demire R. Dermatoglyphics as markers of prenatal disturbances in schizophrenia: a case-control study. Turk J Med Sci. 2010;40(6):917-24

21. Hultman $C M$, Öhnes A. Prenatal and neonatal risk factors for schizophrenia. $\mathrm{Br} J$ Psychiatry. 1997;170:128-33.

22. Geddes J, Lawrie S. Obstetric complication of schizophrenia: a meta analysis. Br J Psychiatry. 1995;167:786-93.

23. Qiu L, Tian L, Pan C, Zhu R, Liu Q, Yan J, et al. Neuroanatomical circuitry associated with exploratory eye movement in schizophrenia: A voxel-based morphometric study. PLoS ONE 2011; 6:10

24. Yıldız AA, Yazar Z, Oğuz H. [Stereoacuity in patients with schizophrenia]. Turk J Ophthalmol. 2010;40(3):176-8. Turkish.

25. Meier MH, Shalev I, Moffitt TE, Kapur SE, Keefe RS, Wong TY, et al. Microvascular abnormalityin schizophrenias shown by retinal imagigng. Am J Psychiatry. 2013;170(12): $1451-9$

26. Shiloh R, Schapir L, Bar-Ziv D, Stryjer R, Konas S, Louis R, et al. Association between corneal temperature and mental status of treatment-resistant schizophrenia inpatients. Eur Neuropsychopharmacol. 2009;19(9):654-8.

27. Shiloh R, Bodinger L, Katz N, Sigler M, Stryjer R, Hermesh $H$, et al. Lower cornea temperature in neuroleptic-treated vs. drug-free schizophrenia patients. Neuropsychobiology. 2003;48(1):1-4.

28. Kruse Hansen F, Ehlers N. Elevated tonometer readings caused by a thick cornea. Acta Ophthalmol (Copenh). 1971;49(5):775-8

29. Wong AC, Wong CC, Yuen NS, Hui SP. Correlational study of central corneal thickness measurements on Hong Kong Chinese using optical coherence tomography, Orbscan and ultrasound pachymetry. Eye (Lond). 2002;16(6):715-21.

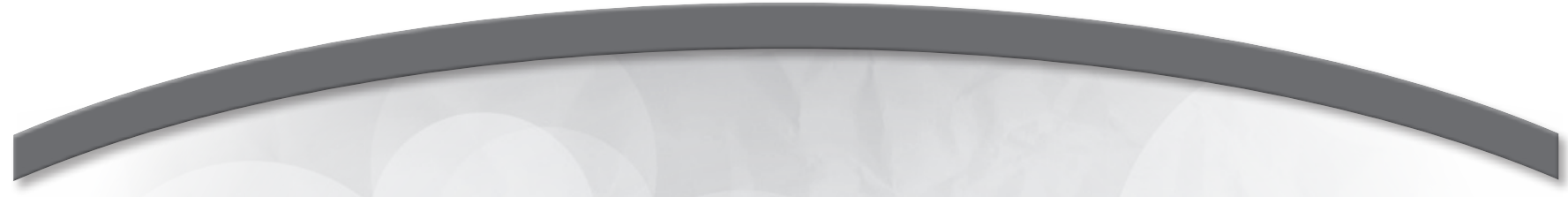

$2^{\circ}$ Congresso de Oftalmologia da Universidade Federal de Goiás

\author{
6 e 7 de novembro de 2015
}

Goiânia - GO

Informações:

E-mail: congressos@brturbo.com.br 